\title{
Associating an ionospheric parameter with major earthquake occurrence throughout the world
}

\author{
D GHOSH${ }^{1}$ and S K Midya ${ }^{1,2, *}$ \\ ${ }^{1}$ Department of Atmospheric Science, University of Calcutta, Kolkata 700 009, India. \\ ${ }^{2}$ Indian Centre for Space Physics, 43 Chalantika, Garia Station Road, Kolkata 700084 , India. \\ *Corresponding author. e-mail: drskm06@yahoo.co.in
}

With time, ionospheric variation analysis is gaining over lithospheric monitoring in serving precursors for earthquake forecast. The current paper highlights the association of major (Ms $\geq 6.0$ ) and medium $(4.0 \leq \mathrm{Ms}<6.0)$ earthquake occurrences throughout the world in different ranges of the Ionospheric Earthquake Parameter (IEP) where 'Ms' is earthquake magnitude on the Richter scale. From statistical and graphical analyses, it is concluded that the probability of earthquake occurrence is maximum when the defined parameter lies within the range of 0-75 (lower range). In the higher ranges, earthquake occurrence probability gradually decreases. A probable explanation is also suggested.

\section{Introduction}

Lithospheric disturbances or crust vibrations affecting ionosphere are an established fact at present. This coupling is more prominent during seismo-tectonics of higher magnitude. An earthquake being one of the most devastating natural calamities, is still unpredictable and thus to predict or forecast earthquakes based on ionospheric precursors has become a highlighted section of research.

Chakrabarti et al. (2005) presented the observations of ionospheric variability by continuous monitoring of VLF signals during the SumatraAndaman earthquake in 2004 and reported that the delay in sunset time occurred $24 \mathrm{hrs}$ prior to the occurrence of earthquake. Study of surface latent heat flux (SLHF) and night-time subionospheric low frequency (LF) radio soundings showed anomalous fluctuations before earthquake. Both SLHF and night-time LF showed complementary nature with SLHF variations being prominent near the epicentral region of coastal earthquake (Cervone et al. 2006). Pulinets and Dunajecka (2007) reported using LAIC (LithosphereAtmosphere-Ionosphere Coupling model) and experimental data of using remote sensing satellites that thermal anomalies due to radon emission in the area of earthquake preparative zone can produce variations of air temperature and relative humidity.

Ganguly (2009) reported that column ozone concentration over a location reaches its lowest value on the day of the major earthquake, increases gradually after the calamity and attains its peak value. Afterwards ozone concentration was found to be normal. Quasi-static electric field anomaly in the upper ionosphere before an earthquake had been observed as an ionospheric precursor (Gousheva et al. 2009). According to LAIC model (Lithosphere-Atmosphere-Ionosphere Coupling model), geochemical, atmospheric and ionospheric parameters are united by a common physical mechanism (Pulinets 2009a, b). Using IAP (ionospheric plasma analyzer) and ISL (Langmuir probe) on DEMETER satellite and GPS

Keywords. Ionospheric parameter; Kleckzek index; sudden ionospheric disturbance. 
data analysis, Akhoondzadeh et al. (2010) showed that electron and ion density variations in the ionosphere occurred over locations prior to strong earthquakes. Jain et al. (2010) reported the anomalies in slab thickness of ionospheric F-region for some days before the main seismic event. They concluded that it may be due to the seismogenic electric field developed above the surface of the earth. Recent investigation has shown that major earthquake ( $\mathrm{Ms} \geq 6.0$ Richter scale) occurrence within $48 \mathrm{hrs}$ is expected when geomagnetic index $\mathrm{K}_{\mathrm{p}}$ attains its minimum value (Midya et al. 2011).

Till date, scientists are continuously trying to discover more and more reliable earthquake precursors so that earthquake prediction may be possible in the near future. The purpose of this paper is to introduce a new parameter - Ionosphere
Earthquake Parameter (IEP) and its close association with the occurrence of major and medium earthquakes throughout the globe.

\section{Data and methodology}

Our data catalogue has been made from websites http://earthquake.usgs.gov/ (for earthquake data) and http://www.ngdc.noaa.gov/ (for SID data) for the period 2000-2006. IEP has been defined on the basis of Kleckzek index of sun - the parameter which represents daily solar activity. Kleckzek index-Q (Kleckzek 1952; Atac 1987), describing the flare activity over $24 \mathrm{hr}$ period is defined by,

$$
Q=i \times t
$$

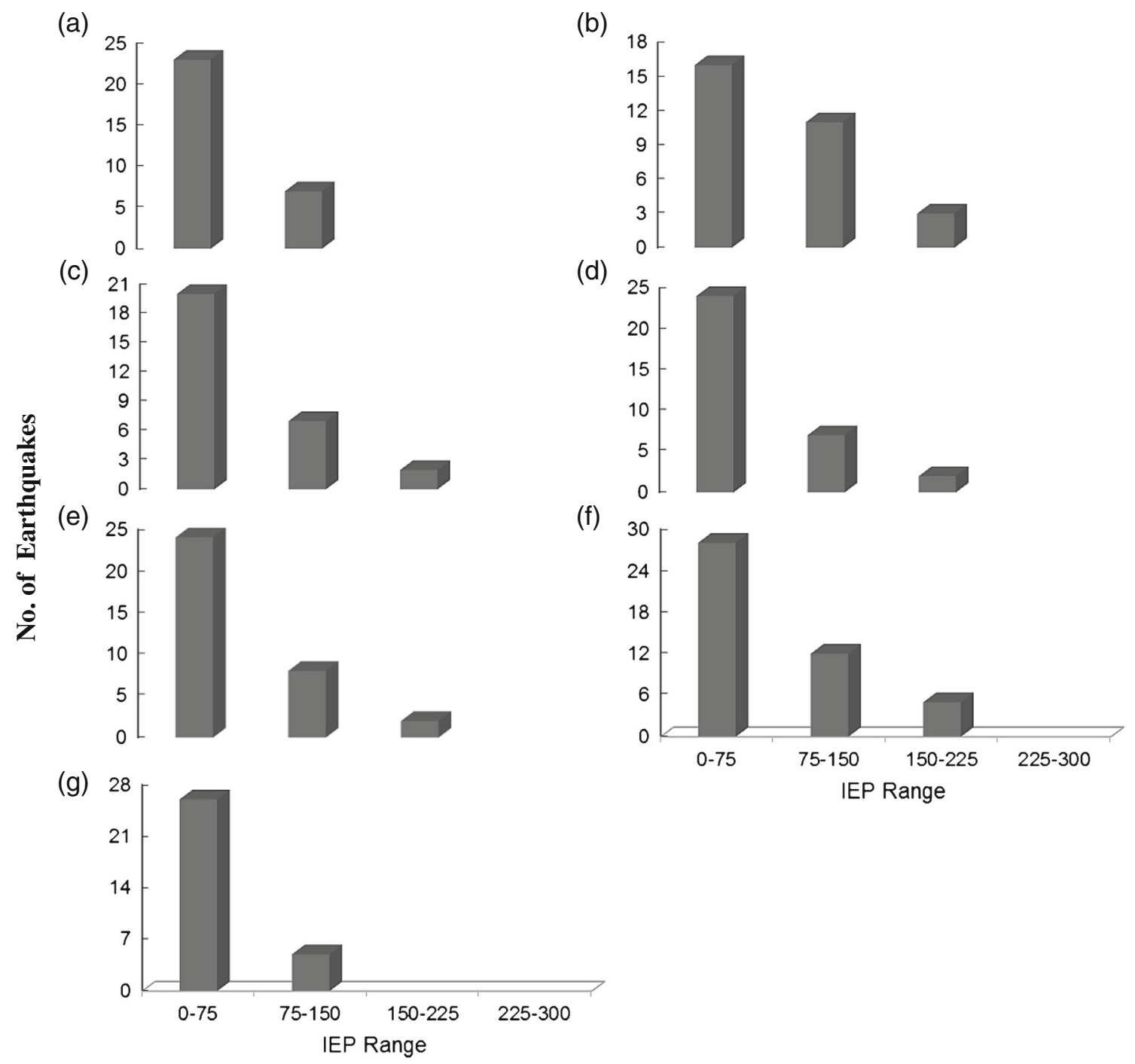

Figure 1. Yearly occurrence of major earthquakes throughout the world plotted in different ranges of IEP of previous day for the period 2000-2006. (a) 2000, (b) 2001, (c) 2002, (d) 2003, (e) 2004, (f) 2005 and (g) 2006. 
where $i$ represents the intensity scale of importance of a flare and $t$ is the duration of the flare in minutes. In relation to the above defined index, the IEP is defined by

$$
\mathrm{IEP}=i_{a} \times t_{d}
$$

where $i_{a}$ is the actual importance of the sudden ionospheric disturbance (SID) and ' $t_{d}$ ' is the duration of the disturbance in minutes. On days with multiple SIDs, average value of the IEP throughout the day has been considered. The ionospheric disturbances are measured by ground observatories over different locations throughout the globe (locations are mentioned on the datasheet of SID obtained from NOAA website).

SID is an abnormal variation in ion/plasma density in the lower ionospheric region (generally Dregion). Upper ionospheric effect, magnetospheric coupling and lower atmosphere (troposphere) primarily affect these ionospheric disturbances. Flare effect includes the blast of intense ultraviolet and X-ray radiation during the solar flare hitting the dayside of the earth, ionizing atmospheric particles, leading to plasma variation and ionospheric disturbance. Earth's magnetic field or the magnetosphere covers a vast area in space thereby preventing earth from the harmful effects of the solar flare. Due to its large cross-section, magnetospheric effect in the ion density variation is also very low. The SID's generally result in sudden increase in radio-wave absorption - most severe in the upper medium frequency (MF) and lower high frequency (HF) ranges and as a result it often interrupts telecommunication systems leading to signal fadeout or communication gap.

\section{Results and discussion}

\subsection{Results}

The occurrence probability of major earthquakes throughout the globe within the defined IEP ranges is depicted in figure 1, where IEP of the previous day of earthquake occurrence is considered. The IEP values obtained are divided into number of slabs with ' 75 ' being the slab-width starting from zero. The number of major earthquakes (Ms $\geq 6.0$ ) occurrence throughout the globe is plotted along the ordinate while IEP range along the abscissa. The figure clearly points out the maximum occurrence probability of earthquakes in the lower IEP range, with probability decreasing with the increase in IEP value. Similar probability trend is also observed for medium earthquakes $(4.0 \leq \mathrm{Ms}<6.0)$, shown in figure 2 , with two-year (2000-2001) variations being presented.

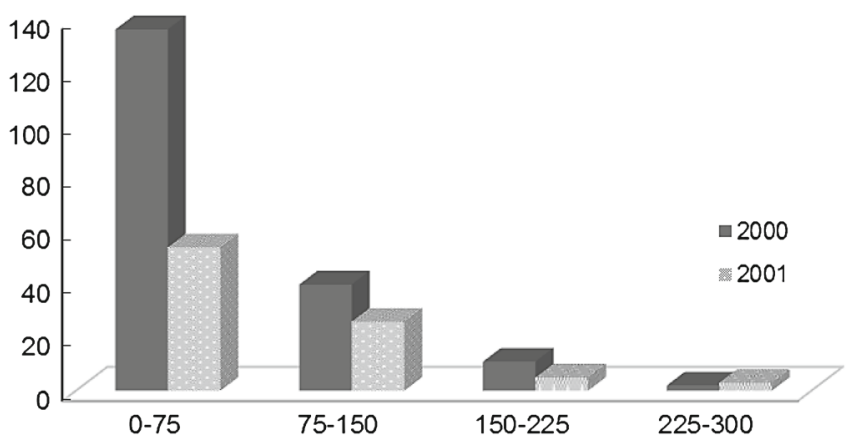

Figure 2. Frequency distribution of medium earthquakes for different ranges of IEP.

The lithospheric crust/cement is a combination of various plates floating over the molten magma. Thus it is under continuous motion throughout the year. So, minor earthquakes $(\mathrm{Ms} \leq 4.0)$ which are occurring large in number (nearly 33,00000/year) are not a section to be worried about (Midya et al. 2011). As minor earthquakes occur frequently, it is quite expected that in all the ranges of IEP value, the number of minor earthquakes will be higher. So, data from medium earthquakes $(4.0 \leq \mathrm{Ms}<6.0)$ is considered as these earthquakes can also cause massive destruction depending upon the topography of the location where the shock is experienced.

Figure 3 presents the daily variation of IEP with earthquake occurrence shown by arrows. The figure at a glance reflects that the trend of occurrence of major earthquake in the lower region of IEP value is greater compared to other regions. The observation is validated using Chi-square $\left(\chi^{2}\right)$ test analysis technique with the analysis details given in table 1. Yearly expected occurrence, actual occurrence and no occurrence of major and medium earthquakes are shown in table 2 with their trend of variation shown in figure 4 . From this figure it is clear that occurrences of major and medium earthquakes nearly follow our expected trend.

\subsection{Discussion}

Discovery of the ionosphere in the early 19th century led to completion of the Global Electric Circuit (GEC) model; though it does not serve as a perfect conductor parallel to the Earth, but the huge potential difference $(150-600 \mathrm{kV}$ ) along with finite electric currents and field which is being maintained between the two spheres bears contributions not only from solar and cosmic radiations but also from electrical processes occurring at the lower atmosphere (Roble and Tzur 1986). But the number density of the charged particles 


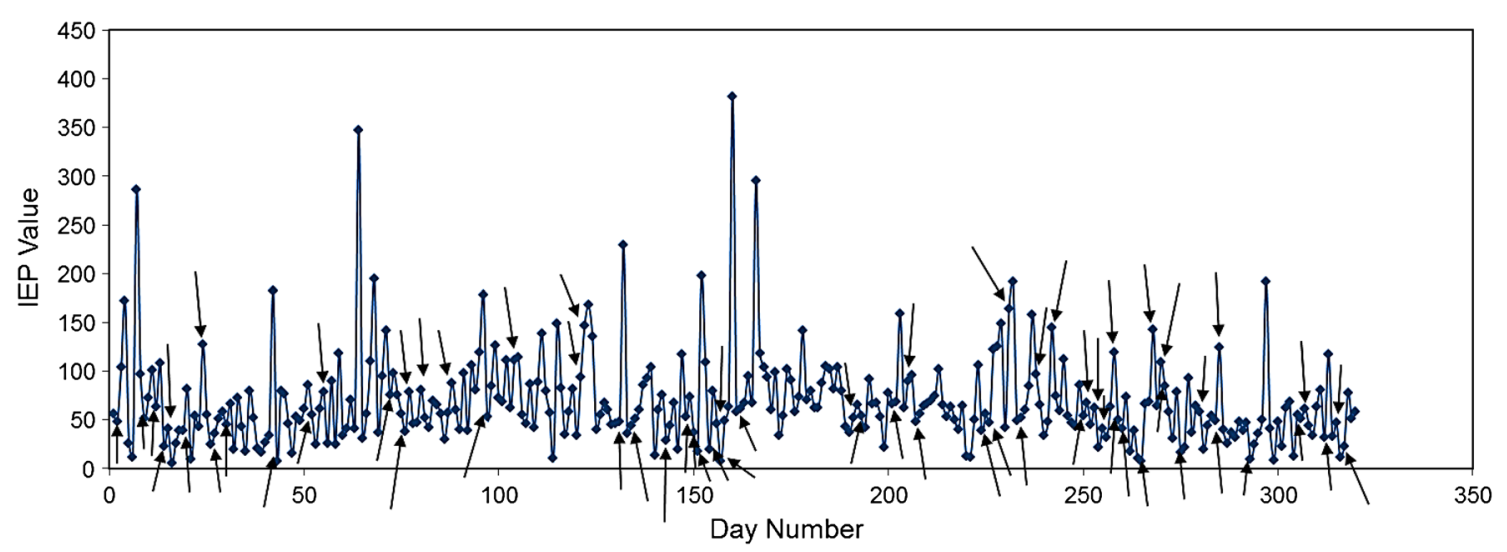

Figure 3. Daily variation of IEP for the year 2002. Upward and downward arrows indicate the occurrence of major earthquakes.

in the ionosphere (total electron content, ion disturbance, etc.) is observed to undergo anomalous behaviour before a major earthquake occurrence. These disturbances are experienced due to the negative field vector intrusion into the ionosphere from the preparative zone of the earthquake, controlled fruitfully through the GEC model by a horizontal ion drift process with a positive downfield through a thunderstorm activity, discharging over regions of fair weather (Pulinets and Boyarchuk 2004; Pulinets 2009a, b). The generation of the negative vertical electric field is mainly attributed to the increased emanation of excited radon molecules from the ground.

\subsubsection{Pathway for radon emission}

Radioactive decay of nuclear materials ( $\mathrm{U}^{238}$, $\mathrm{Th}^{232}$, etc.) underneath the soil surface leads to formation of radons (illustrated below), which get entrapped within the various layers of the soil. A fraction of the formed radon is with held by the solid matrix while the left over fraction migrates through the pores and faults underneath. High density $\left(9.73 \mathrm{~kg} / \mathrm{m}^{3}\right)$ and lower mobility $\left(\leq 10^{-3} \mathrm{~cm} / \mathrm{s}\right)$ restricts radon flow through the porous soil layers by diffusion and advection. Thus the carrier gas mixture also termed as 'geogas' $\left(\mathrm{CH}_{4}\right.$, $\mathrm{CO}_{2}, \mathrm{~N}_{2}$, etc.) (Etiope and Martinelli 2002) guides radons to the surface. Since the fault zone provides greater pathways, gas migration is facilitated through these channel faults instead of the pore channels.

Before a seismic activity, the increase in stress and strain of the underneath surface strata and rock layers leads to the development of new faults and fissures along with the existing one. The increase in stress within the different tectonic plates guides the fluid underneath to rise to the surface (Khilyuk et al. 2000; Ghosh et al. 2009). The solubility property of radon in water (King 1980; Khilyuk et al. 2000) allows it to migrate to different and distant locations of the earth about to experience quake shocks following the bubble flow theory which is recognized as the most rapid gas migration mechanism (Vàrhegyi et al. 1992). Radons emanate continuously from the surface throughout the year, with concentration anomaly observed near and around the epicentral zone a few days before the main shock.

$$
\begin{aligned}
& { }^{238} \mathrm{U}_{92} \rightarrow{ }^{234} \mathrm{Th}_{90} \rightarrow{ }^{234} \mathrm{~Pa}_{91} \rightarrow{ }^{234} \mathrm{U}_{92} \\
& \rightarrow{ }^{230} \mathrm{Th}_{90} \rightarrow{ }^{226} \mathrm{Ra}_{88} \\
& \rightarrow{ }^{222} \mathrm{Rn}_{86} \text { (stable radon formed) }
\end{aligned}
$$

\subsubsection{General mechanism for ion cluster formation}

The emitted radon molecules from the earth's surface strata are highly excited, energized particles. They collide with the atmospheric constituents [viz., aerosols and other gaseous components $\left(\mathrm{CO}_{2}, \mathrm{SO}_{\mathrm{x}}, \mathrm{NO}_{\mathrm{x}}\right.$, etc. $\left.)\right]$ of the planetary boundary layer making them activated and charged. By this collisional process the mobility of the activated and energized aerosol particles increases. But the mobility of those particles is checked as these highly charged particles including radons become centres of water condensation. Thus, the mobility of the particles getting hydrated decreases \{ionic mobility is given by $\mu=q / m_{i} \nu_{i}$, where $\mu$ is the ionic mobility, $q$ is the ion charge, $m_{i}$ is the ion mass and $\nu_{i}$ is the ion-collision frequency\}. Nearly 100 to 200 water molecules get attached to a single ion but sometimes over 1000 
Table 1. Statistical calculation of expected and unexpected occurrence of major earthquakes (monthwise) and occurrence percentage.

\begin{tabular}{|c|c|c|c|c|c|c|c|}
\hline Year & Month & $\begin{array}{c}\text { Expected } \\
\text { occurrence } \\
\text { (no. of days) }\end{array}$ & $\begin{array}{c}\text { Actual } \\
\text { occurrence } \\
\text { (no. of days) }\end{array}$ & $\begin{array}{l}\chi^{2} \text { for expected } \\
\text { major earthquake } \\
\quad(\text { monthwise })\end{array}$ & $\begin{array}{l}\text { Unexpected } \\
\text { occurrence } \\
\text { (no. of days) }\end{array}$ & $\begin{array}{c}\text { Actual } \\
\text { occurrence } \\
\text { (no. of days) }\end{array}$ & $\begin{array}{c}\chi^{2} \text { for unexpected } \\
\text { major earthquake } \\
\text { (monthwise) }\end{array}$ \\
\hline \multirow{12}{*}{2000} & Jan & 17 & 4 & 1.46 & 14 & 0 & 1.82 \\
\hline & Feb & 14 & 0 & 1.82 & 15 & 0 & 1.95 \\
\hline & Mar & 17 & 0 & 2.21 & 14 & 0 & 1.82 \\
\hline & Apr & 17 & 0 & 2.21 & 13 & 0 & 1.69 \\
\hline & May & 14 & 2 & 0.02 & 17 & 0 & 2.21 \\
\hline & June & 14 & 8 & 21.04 & 16 & 1 & 0.56 \\
\hline & July & 19 & 3 & 0.12 & 12 & 1 & 0.20 \\
\hline & Aug & 17 & 2 & 0.02 & 14 & 0 & 1.82 \\
\hline & Sept & 19 & 0 & 2.47 & 11 & 0 & 1.43 \\
\hline & Oct & 15 & 2 & 0.00 & 16 & 2 & 0.00 \\
\hline & Nov & 18 & 1 & 0.76 & 12 & 1 & 0.20 \\
\hline & Dec & 21 & 2 & 0.19 & 10 & 2 & 0.38 \\
\hline \multirow{12}{*}{2001} & Jan & 14 & 1 & 0.37 & 17 & 1 & 0.66 \\
\hline & Feb & 21 & 5 & 1.90 & 7 & 0 & 0.91 \\
\hline & Mar & 22 & 3 & 0.01 & 9 & 1 & 0.02 \\
\hline & Apr & 10 & 0 & 1.30 & 20 & 2 & 0.14 \\
\hline & May & 16 & 1 & 0.56 & 15 & 2 & 0.00 \\
\hline & June & 14 & 1 & 0.37 & 16 & 3 & 0.41 \\
\hline & July & 11 & 0 & 1.43 & 20 & 0 & 2.60 \\
\hline & Aug & 19 & 1 & 0.87 & 12 & 2 & 0.13 \\
\hline & Sept & 13 & 0 & 1.69 & 17 & 1 & 0.66 \\
\hline & Oct & 16 & 2 & 0.00 & 15 & 1 & 0.46 \\
\hline & Nov & 11 & 0 & 1.43 & 19 & 0 & 2.45 \\
\hline & Dec & 14 & 2 & 0.02 & 17 & 1 & 0.66 \\
\hline \multirow{12}{*}{2002} & Jan & 19 & 1 & 0.87 & 12 & 1 & 0.20 \\
\hline & Feb & 20 & 0 & 2.60 & 8 & 0 & 1.04 \\
\hline & Mar & 15 & 3 & 0.57 & 16 & 0 & 2.08 \\
\hline & Apr & 16 & 1 & 0.56 & 14 & 1 & 0.37 \\
\hline & May & 17 & 2 & 0.02 & 14 & 1 & 0.37 \\
\hline & June & 15 & 2 & 0.00 & 15 & 1 & 0.46 \\
\hline & July & 13 & 0 & 1.69 & 18 & 1 & 0.76 \\
\hline & Aug & 23 & 2 & 0.33 & 8 & 0 & 1.04 \\
\hline & Sept & 19 & 1 & 0.87 & 11 & 1 & 0.13 \\
\hline & Oct & 17 & 5 & 3.54 & 14 & 0 & 1.82 \\
\hline & Nov & 23 & 2 & 0.33 & 7 & 3 & 4.81 \\
\hline & Dec & 20 & 1 & 0.98 & 11 & 0 & 1.43 \\
\hline \multirow{12}{*}{2003} & Jan & 19 & 1 & 0.87 & 12 & 0 & 1.56 \\
\hline & Feb & 17 & 1 & 0.66 & 11 & 0 & 1.43 \\
\hline & Mar & 19 & 5 & 2.60 & 12 & 0 & 1.56 \\
\hline & Apr & 22 & 2 & 0.26 & 8 & 0 & 1.04 \\
\hline & May & 10 & 1 & 0.07 & 21 & 4 & 0.60 \\
\hline & June & 13 & 4 & 3.17 & 17 & 3 & 0.29 \\
\hline & July & 14 & 2 & 0.02 & 17 & 1 & 0.66 \\
\hline & Aug & 17 & 0 & 2.21 & 14 & 0 & 1.82 \\
\hline & Sept & 18 & 4 & 1.18 & 12 & 0 & 1.56 \\
\hline & Oct & 16 & 3 & 0.41 & 15 & 0 & 1.95 \\
\hline & Nov & 19 & 1 & 0.87 & 11 & 1 & 0.13 \\
\hline & Dec & 16 & 0 & 2.08 & 15 & 2 & 0.00 \\
\hline
\end{tabular}


Table 1. (Continued.)

\begin{tabular}{|c|c|c|c|c|c|c|c|}
\hline Year & Month & $\begin{array}{c}\text { Expected } \\
\text { occurrence } \\
\text { (no. of days) }\end{array}$ & $\begin{array}{c}\text { Actual } \\
\text { occurrence } \\
\text { (no. of days) }\end{array}$ & $\begin{array}{c}\chi^{2} \text { for expected } \\
\text { major earthquake } \\
\text { (monthwise) }\end{array}$ & $\begin{array}{l}\text { Unexpected } \\
\text { occurrence } \\
\text { (no. of days) }\end{array}$ & $\begin{array}{c}\text { Actual } \\
\text { occurrence } \\
\text { (no. of days) }\end{array}$ & $\begin{array}{c}\chi^{2} \text { for unexpected } \\
\text { major earthquake } \\
\text { (monthwise) }\end{array}$ \\
\hline \multirow{12}{*}{2004} & Jan & 17 & 0 & 2.21 & 14 & 0 & 1.82 \\
\hline & Feb & 15 & 1 & 0.46 & 14 & 1 & 0.37 \\
\hline & Mar & 20 & 0 & 2.60 & 11 & 0 & 1.43 \\
\hline & Apr & 18 & 4 & 1.18 & 12 & 0 & 1.56 \\
\hline & May & 23 & 3 & 0.00 & 8 & 1 & 0.00 \\
\hline & June & 19 & 3 & 0.12 & 11 & 1 & 0.13 \\
\hline & July & 13 & 1 & 0.28 & 18 & 3 & 0.19 \\
\hline & Aug & 13 & 0 & 1.69 & 18 & 0 & 2.34 \\
\hline & Sept & 7 & 2 & 1.31 & 23 & 3 & 0.00 \\
\hline & Oct & 16 & 3 & 0.41 & 15 & 0 & 1.95 \\
\hline & Nov & 19 & 4 & 0.95 & 11 & 1 & 0.13 \\
\hline & Dec & 15 & 1 & 0.46 & 16 & 1 & 0.56 \\
\hline \multirow{12}{*}{2005} & Jan & 16 & 3 & 0.41 & 15 & 4 & 2.16 \\
\hline & Feb & 16 & 5 & 4.11 & 12 & 0 & 1.56 \\
\hline & Mar & 14 & 5 & 5.57 & 17 & 0 & 2.21 \\
\hline & Apr & 14 & 5 & 5.57 & 16 & 3 & 0.41 \\
\hline & May & 18 & 3 & 0.19 & 13 & 1 & 0.28 \\
\hline & June & 12 & 2 & 0.13 & 18 & 3 & 0.19 \\
\hline & July & 10 & 1 & 0.07 & 21 & 0 & 2.73 \\
\hline & Aug & 13 & 1 & 0.28 & 18 & 0 & 2.34 \\
\hline & Sept & 12 & 1 & 0.20 & 18 & 0 & 2.34 \\
\hline & Oct & 5 & 0 & 0.65 & 26 & 1 & 1.67 \\
\hline & Nov & 6 & 1 & 0.06 & 24 & 3 & 0.00 \\
\hline & Dec & 7 & 3 & 4.81 & 24 & 0 & 3.12 \\
\hline \multirow{12}{*}{2006} & Jan & 10 & 3 & 2.23 & 21 & 1 & 1.09 \\
\hline & Feb & 8 & 0 & 1.04 & 20 & 0 & 2.60 \\
\hline & Mar & 12 & 2 & 0.13 & 19 & 0 & 2.47 \\
\hline & Apr & 15 & 5 & 4.79 & 15 & 1 & 0.46 \\
\hline & May & 5 & 0 & 0.65 & 26 & 1 & 1.67 \\
\hline & June & 8 & 1 & 0.00 & 22 & 0 & 2.86 \\
\hline & July & 5 & 1 & 0.19 & 26 & 0 & 3.37 \\
\hline & Aug & 13 & 3 & 1.02 & 18 & 0 & 2.34 \\
\hline & Sept & 1 & 1 & 5.83 & 29 & 0 & 3.76 \\
\hline & Oct & 9 & 5 & 12.57 & 22 & 0 & 2.86 \\
\hline & Nov & 13 & 3 & 1.02 & 17 & 0 & 2.21 \\
\hline & Dec & 11 & 2 & 0.23 & 20 & 3 & 0.06 \\
\hline Total sum & & 1248 & 162 & 132.40 & 1309 & 73 & 105.44 \\
\hline
\end{tabular}

Expected occurrence percentage $=12.98 \%$ while unexpected occurrence percentage $=5.58 \%$. From the above table, chisquare for expected $=132.40$, while for unexpected $=105.44$.

$\mathrm{H}_{2} \mathrm{O}$ molecules can bind to a single ion depending upon the charge density of the ion and water availability in the surrounding atmosphere. With the increase in ion hydration, the ion size and mass increase significantly resulting in the decrease in columnar conductivity of the non-conductive air the drop in ion mobility is immediately reflected in the electrical conductivity $\sigma$; given by $\sigma=$ $n|q| \mu$, where $n$ is the collision frequency, $q$ is ion charge and $\mu$ is ionic mobility $\}$ where the above charge clusters are formed about $4-5 \mathrm{~m}$ above the ground thereby developing an electric field near the surface (Pulinets 2004, 2009a, b).

\subsubsection{Vertical electric field intrusion}

In normal atmosphere, with minimum ion clusters at the surface, the columnar conductivity increases with altitude exponentially (Roble and Tzur 1986). 
Table 2. Data for expected, actual and no occurrence of major and medium earthquake for the period 2000-2006*.

\begin{tabular}{|c|c|c|c|c|c|}
\hline Year & $\begin{array}{c}\text { Total } \\
\text { expected } \\
\text { occurrence }\end{array}$ & $\begin{array}{l}\text { Actual occurrence } \\
\text { of major } \\
\text { earthquake }\end{array}$ & $\begin{array}{l}\text { Actual occurrence } \\
\text { of medium } \\
\text { earthquake }\end{array}$ & $\begin{array}{l}\text { Total occurrence of } \\
\text { major and medium } \\
\text { earthquake }\end{array}$ & $\begin{array}{c}\text { No occurrence of } \\
\text { major and medium } \\
\text { earthquake }\end{array}$ \\
\hline 2000 & 202 & 24 & 144 & 168 & 32 \\
\hline 2001 & 181 & 16 & 140 & 156 & 25 \\
\hline 2002 & 217 & 20 & 150 & 170 & 47 \\
\hline 2003 & 200 & 24 & 132 & 156 & 44 \\
\hline 2004 & 195 & 22 & 130 & 152 & 43 \\
\hline 2005 & 143 & 30 & 78 & 108 & 35 \\
\hline 2006 & 110 & 26 & 68 & 94 & 16 \\
\hline
\end{tabular}

${ }^{*}$ Figures corresponding to each year in the table above represent number of days.

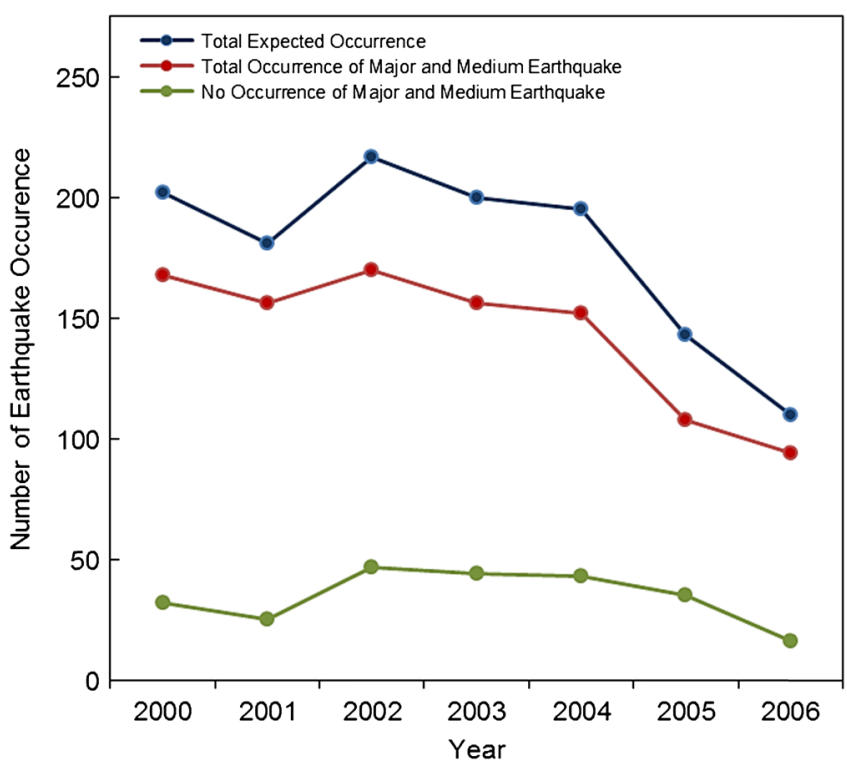

Figure 4. Occurrence trends of expected, actual and no major and medium earthquakes for the period 2000-2006.

But with the decrease in atmospheric columnar conductivity by the formation of ion clusters near the surface, the vertical electric field of the column therefore increases before major earthquakes (since conductivity and electric field are inversely proportional) over the preparative zone.

Ionospheric disturbances are related to ion or electron concentration variations in the lower ionosphere, measured as frequency signals emitted from the disturbance. The preparative zone experiences a decrease in total electron count (TEC) before strong earthquakes (Liu et al. 2001; Namgaladze et al. 2009). The two way interaction of lower electron content with upward electric field results in the net lowering of IEP value prior to strong earthquakes. Cases registered with increase in TEC

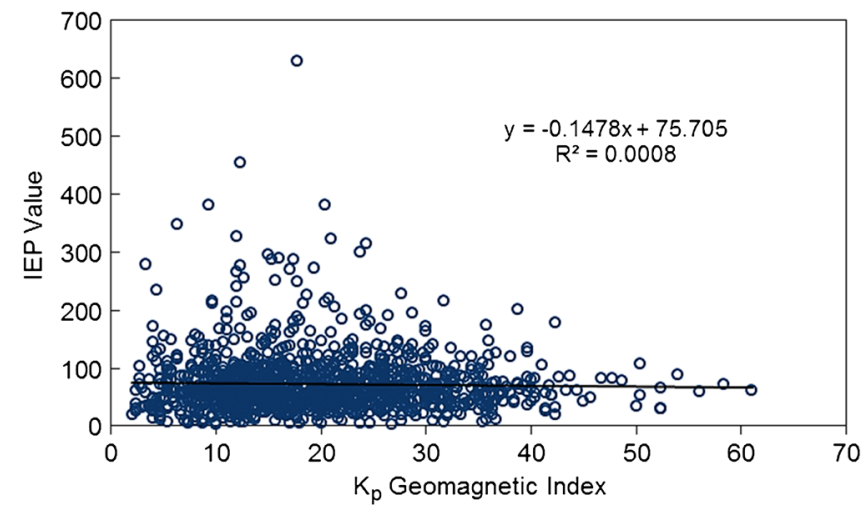

Figure 5. Variation of IEP with $\mathrm{K}_{\mathrm{p}}$ geomagnetic index for 2000-2003.

value (Pulinets and Tsybulya 2010; Klimenko et al. 2011) actually led to results with higher IEP value before major earthquakes. Geological structures and topographical conditions play a vital role in varying radon concentrations. Sometimes the concentration of radons may not be sufficient to create the significant large-scale variations within the ionosphere. Instead, 'scintillations' of the columnar resistance and a corresponding regional variability will be observed in the ionosphere.

In figure 5, contribution of earth's geomagnetic index ' $K_{\mathrm{p}}$ ' to IEP is studied. Low correlation co-efficient value $\left(R^{2}=8 \times 10^{-4}\right)$ and slope $(-0.1478)$ of the linear fit curve clearly depicts that these two parameters (IEP and $K_{p}$ ) are independent of each other. Thus, magnetospheric contribution in ionospheric disturbance is quite negligible. Similar independent relationship is obtained in figures 6 and 7 where solar effects on IEP are studied with sunspot numbers and X-ray flux. With the same statistical calculation, very low $\mathrm{R}^{2}$ value $\left[2 \times 10^{-3}\right.$ (with sunspot) and $2.17 \times 10^{-2}$ (with X-ray flux)] in both the cases is observed 


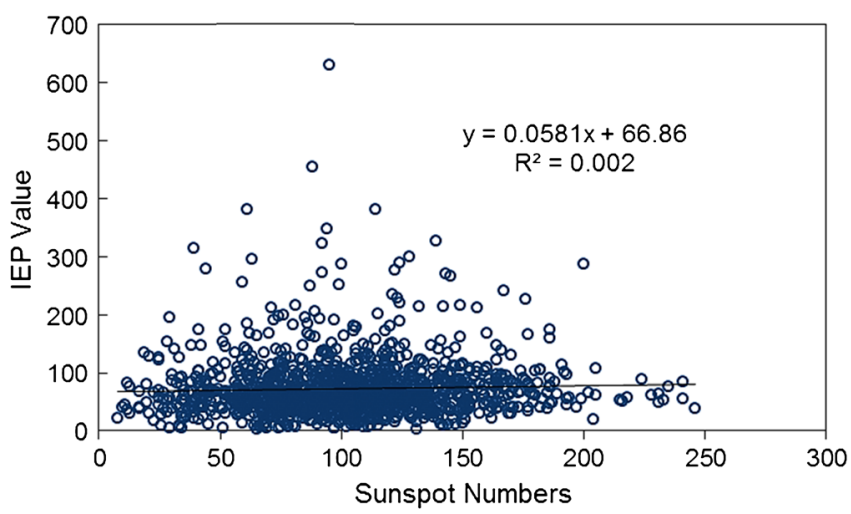

Figure 6. Variation of IEP with sunspot number for 2000-2003.

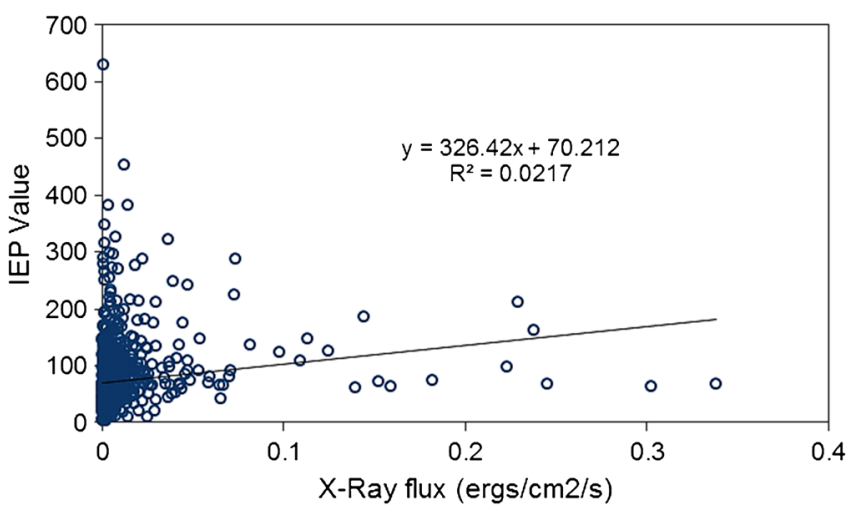

Figure 7. Variation of IEP with X-ray flux for 2000-2003.

reflecting low flare contribution over IEP. Variation of IEP is thus considered separately for associating major earthquake occurrence. Our presented analysis shows that the probability of major earthquake is greater when IEP value lies between zero and 75 .

\section{Conclusion}

It is concluded that the probability of major earthquake occurrences throughout the world is maximum when the defined parameter lies within the range of $0-75$ (lower range). In the higher ranges, earthquake occurrence probability decreases. It is shown that geomagnetic disturbance index $\left(\mathrm{K}_{\mathrm{p}}\right)$, sunspot numbers and X-ray flux variations have no inter-relationships with IEP. Earthquake occurrence in the lower value of IEP may be due to the interaction of total electron content decrease over the preparative zone in the ionosphere and vertical field intrusion from the ground.
This two way interaction results in net lowering of the duration of SID and finally of IEP value.

\section{Acknowledgements}

The authors would like to thank NOAA for making ionospheric data freely available on their websites, United States Geological Survey (USGS) for making earthquake data retrieval or access easy and comfortable thereby supporting researchers to proceed with new ideas; and also a special thanks to Prof. Sergey Pulinets (Fiodorov Institute of Applied Geophysics, Moscow Center of Ionosphere Monitoring) for his kind help to the author (D Ghosh) by providing necessary journal papers and for answering many of his questions regarding earthquake and ionospheric precursors which helped in preparing this paper.

\section{References}

Akhoondzadeh M, Parrot M and Saradjian M R 2010 Electron and ion density variations before strong earthquakes $(\mathrm{M} \geq 6.0)$ using DEMETER and GPS Data; Nat. Hazards Earth Syst. Sci. 10 7-18.

Atac T 1987 Time variation of flare index during 21st Solar Cycle; Astrophys. Space Sci. 135 201-205.

Cervone G, Maekewa S, Singh R P, Hayakawa M, Kafatos M and Shvets A 2006 Surface latent heat flux and nighttime LF anomalies prior to the $\mathrm{M}_{\mathrm{w}}=8.3$ Tokachi-Oki earthquake; Nat. Hazards Earth Syst. Sci. 6 109-114.

Chakrabarti K, Saha M, Khan R, Mandal S, Acharyya K and Saha R 2005 Possible detection of ionospheric disturbances during the Sumatra-Andaman islands earthquakes of December 2004; Indian J. Radio Space Phys. 34 314-318.

Etiope G and Martinelli G 2002 Migration of carrier and trace gases in the geosphere: An overview; Phys. Earth Planet. Interiors 129(3-4) 185-204.

Ganguly N D 2009 Variation of atmospheric ozone concentration following strong earthquake; Int. J. Remote Sens. 30(2) 349-356.

Ghosh D, Deb A and Sengupta R 2009 Anomalous radon emission as precursor of earthquake; J. Appl. Geophys. 69 67-81.

Gousheva M, Danov D, Hristov P and Matova M 2009 Ionospheric quasi-static electric field anomalies during seismic activity in August-September 1981; Nat. Hazards Earth Syst. Sci. 9 3-15.

Jain S K, Panda G and Vijay S K 2010 Study of variation in slab thickness of ionospheric F-region during earthquake by wavelet analysis; Ind. J. Phys. 84(4) 359-365.

Khilyuk L F, Chilingar G V, Robertson Jr J O and Endres B 2000 Gas Migration - Events Preceding Earthquakes; ISBN: 0-88415-430-0.

King C Y 1980 Episodic radon changes in subsurface soil gas along active faults and possible relation to earthquakes; J. Geophys. Res. 85(86) 3065-3078.

Kleckzek J 1952 Publ. Centr. Astron. Inst., Czechoslovakia, No. 22.

Klimenko M V, Klimenko V V, Zakharenkova I E, Pulinets S A, Zhao B and Tsidilina M N 2011 Formation 
mechanism of great positive TEC disturbances prior to Wenchuan earthquake on May 12, 2008; Adv. Space Res. 48 488-499.

Liu J Y, Chen Y I, Chuo Y J and Tsai H I 2001 Variations of ionospheric total electron content during the Chi-Chi earthquake; Geophys. Res. Lett. 28(7) 1383-1386.

Midya S K, Dutta A K and Panda P 2011 Association of major earthquakes (magnitude $\geq 6$ Richter Scale) with geomagnetic disturbance index $\mathrm{K}_{\mathrm{p}}$ during the period 2001-2007; Mausam 62(2) 245-252.

Namgaladze A A, Zolotov O V, Zakharenkova I E, Shagimuratov I I and Martynenko O V 2009 Ionospheric total electron content variations observed before earthquakes 2009: Possible physical mechanism and modeling; Proc. MSTU 12(2) 308-315.

Pulinets S A 2004 Ionospheric precursors of earthquakes: Recent advances in theory and practical applications; TAO 15(3) 413-435.

Pulinets S 2009 Lithosphere-atmosphere-ionosphere coupling (LAIC) model-Electromagnetic phenomena associated with earthquakes; Transworld Research Network, ISBN: 978-81-7895-297-0, pp. 235-254.
Pulinets S A 2009 Physical mechanism of the vertical electric field generation over active tectonic faults; Adv. Space Res. 44 767-773.

Pulinets S and Boyarchuk K 2004 Ionospheric Precursors of Earthquakes; Springer Berlin-Heidelberg-New York, ISBN: 3-540-20839-9.

Pulinets S A and Dunajecka M A 2007 Specific variations of air temperature and relative humidity around the time of Michoacan earthquake M8.1 Sept. 19, 1985 as a possible indicator of interaction between tectonic plates; Tectonophys. 431(1-4) 221-230.

Pulinets S A and Tsybulya K G 2010 Unique variations of the total electron content in the preparation period of Haitian Earthquake (M7.9) on January 12 2010; Geomagn. Aeron. 50(5) 686-689.

Roble R G and Tzur I 1986 The global atmospheric-electrical circuit - The Earth's Electrical Environment; National Academic Press, Washington DC, pp. 206-231.

Vàrhegyi A, Hakl J, Monnin M, Morin J P and Seidel J L 1992 Experimental study of radon transport in water as test for a transportation microbubble model; J. Appl. Geophys. 29(1) 37-46. 